\title{
Comparison of immune response generated against Japanese encephalitis virus envelope protein expressed by DNA vaccines under macrophage associated versus ubiquitous expression promoters
}

\author{
Mohammad Feraz Ahsan and Milind M Gore
}

\begin{abstract}
Background: Japanese encephalitis virus (JEV) is the leading cause of viral encephalitis, with $\sim 50,000$ cases reported annually worldwide. Vaccination is the only measure for prevention. Recombinant vaccines are an efficient and safe alternative for formalin inactivated or live attenuated vaccines. Nowadays, incorporation of molecular adjuvants has been the main strategy for melioration of vaccines. Our attempt of immunomodulation is based on targeting antigen presenting cells (APC) "majorly macrophages" by using macrosialin promoter. We have compared the immune response of the constructed plasmids expressing JEV envelope (E) protein under the control of aforesaid promoter and cytomegalovirus (CMV) immediate early promoter in mouse model. Protection of immunized mice from lethal challenge with JEV was also studied.
\end{abstract}

Results: The E protein was successfully expressed in the macrophage cell line and was detected using immunofluorescence assay (IFA) and Western blotting. APC expressing promoter showed comparable expression to CMV promoter. Immunization of mice with either of the plasmids exhibited induction of variable JEV neutralizing antibody titres and provided protection from challenge with a lethal dose of JEV. Immune splenocytes showed proliferative response after stimulation with the JEV antigen (Ag), however, it was higher for CMV promoter. The magnitude of immunity provided by APC dominant promoter was non-significantly lower in comparison to CMV promoter. More importantly, immune response directed by APC promoter was skewed towards Th1 type in comparison to CMV promoter, this was evaluated by cytokine secretion profile of immune splenocytes stimulated with JEV Ag.

Conclusions: Thus, our APC-expressing DNA vaccination approach induces comparable immunity in comparison to ubiquitous promoter construct. The predominant Th1 type immune responses provide opportunities to further test its potency suitable for response in antiviral or anticancer vaccines.

\section{Background}

JEV belongs to the family Flaviviridae. It is transmitted to humans by mosquitoes leading to the infection of central nervous system and encephalitis. JEV has covered a vast geographic area of Asia and parts of Oceania [1]. Nearly half of the human population falls in countries

\footnotetext{
* Correspondence: gore.milind@gmail.com
National Institute of Virology, Pashan Campus, 130/1, Sus Road, Pashan,

* Correspondence: gore.milind@gmail.com
National Institute of Virology, Pashan Campus, 130/1, Sus Road, Pashan, Pune, India
} Pune, India

where JEV occurs, globally 50,000 cases are reported with 15,000 mortality rate per year [2-5].

Vaccination is the only way in controlling JEV outbreaks. Several such vaccines have been used with considerable success. The only WHO recommended vaccine used worldwide was BIKEN which was a formalin inactivated vaccine from infected mouse brain. Live-attenuated JE vaccine (SA 14-14-2) prepared in infected primary hamster kidney cells is used in China for many years and is in use by other countries like India and Nepal in recent 
times. Recently, Vero cell derived inactivated JE vaccine has also been licensed. Chimeric Yellow fever-JE vaccine is undergoing phase III trial [6]. Each of these vaccines have their own drawbacks $[7,8]$, and as such there is a need for the development of safer and cost effective vaccine with higher potency which can elicit both the arms of immune response, such as DNA vaccines [9].

JEV is a single stranded, positive sense RNA virus. The genomic RNA is $\sim 11 \mathrm{~kb}$ with single open reading frame (ORF) that encodes structural protein (capsid (C), premembrane (prM) and E) followed by seven nonstructural protein (NS1 to NS5) [10,11]. E protein plays a major role in the infection, such as receptor binding and membrane fusion [12]. E protein induces virus neutralizing antibodies and these have been shown to neutralize virus activity through passive administration in mice model also [13]. For proper folding of E protein, co-synthesis of prM protein is required [14]. Subvirus particle with only prM and E protein has also generated protection against lethal JEV infection [15]. DNA vaccine encoding $\mathrm{E}$ protein is considered to be highly effective in providing protective immunity when compared with other proteins of JEV [16].

With the growing knowledge of molecular information on JEV, recombinant vaccines using various approaches [17] with different gene products [18-20] have been tried. Such vaccines have shown considerable success albeit with some shortcomings; either in terms of evoking suboptimal response or not maintaining the balance between Th1 and Th2 response [21]. Therefore the present attention has shifted towards the improvement of DNA vaccine modulated through several immunological adjuvants, such as the use of liposomes [22], inclusion of CpG motif [23], coexpressing cytokines and costimulatory molecules along with the target gene [24], exploring different routes of administration of vaccine [25-27], targeting the vaccine to specific cells [28] or endosomal/lysosomal compartment [29].

One such optimization is to target the antigen expression in professional APC by using promoters active only in APC [30]. Dendritic cell (DC) as an APC have preference over macrophage and B cells as a potent cell in priming and stimulating naïve $\mathrm{T}$ cells. Langerhans cells have been targeted using Dectin-2 promoter [31]. For the treatment of HIV-1, APC have been targeted [32]. Lentiviral vectors were used to deliver the gene into APC [33].

Immune response to any antigen is a highly intricate and balanced mechanism. To prevent unwanted immune responses like autoimmunity, hypersensitivity and to induce long term antigen specific immunity, specific cells with appropriate cytokine and cell surface antigen milieu have been devised by immune system. Presentation of antigen through APC would thus be the most desirable approach while developing newer vaccine. Although, DC specific promoter has shown promising results, meagrely targeting DC was reported to be insufficient to optimally induce $\mathrm{T}$ cell immunity $[34,35]$. Therefore the role of other professional APC (Macrophage and B-cells) needs to be considered. Studies suggest macrophages are potent enough to stimulate naïve CD8 $+\mathrm{T}$ cells to proliferate and mature [36] and could be as good as DC in cross presentation of antigen [37]. Thus there is a need to explore promoters which could be active also in other cells of APC and just not a single population.

Our earlier work for initial screening of promoters was carried out in macrophage and non-macrophage cell lines at the level of mRNA and protein using GFP as a reporter system [38]. Briefly, three promoters were selected based on their known expression profiles. Macrosialin, is a glycoprotein expressed specifically in murine monocytes and macrophages and to a lesser extent by DC [39-41]. Activity of this promoter along with two other promoters; Emr-1 [42-44] and Beta-5 Integrin $[45,46]$, was compared with immediate early promoter of CMV. Macrosialin was chosen for further studies as it showed the highest expression amongst the APC expressing promoters albeit to a lesser extent in comparison to CMV promoter.

To study the effect of APC dominant expression as against ubiquitous expression on protective immune response, JEV system has been used. We report here studies carried out by immunizing mice with plasmids expressing JEV E protein under macrosialin promoter and comparing it with CMV promoter in terms of protective immunity and immune balance.

\section{Methods}

\section{Virus and Antigen}

JEV strain 733913 was used in all experiments [47]. Virus pools were prepared for ex vivo experiments in porcine stable kidney (PS) cells. For in vivo experiment two days old infant mouse brain derived virus pool suspended in $0.75 \%$ bovine serum albumin (BSA) in PBS was used. Virus stocks were stored at -70 in aliquots and titrated using plaque assay and in two months old mice group respectively. Mouse brain antigen (MbrAg) for mice inoculation was prepared in borate saline containing $8.5 \%$ sucrose, homogenized and inactivated with $\beta$-propiolactone. For ex vivo studies, cell culture derived virus antigen as cell slurry was used [48].

\section{Cell Culture}

PS cells (National Center for Cell Sciences (NCCS), Pune, India) were maintained in minimal essential medium (MEM) (Sigma) supplemented with $2 \mathrm{mmol} / \mathrm{l} \mathrm{L-glu-}$ tamine and $10 \%$ fetal bovine serum (FBS) (Gibco, USA). Whereas RAW264.7 cells (NCCS, Pune, India) were maintained in high glucose DMEM with $10 \%$ FBS 
(Gibco, USA) supplemented with penicillin $(100 \mathrm{IU} / \mathrm{ml})$ and streptomycin $(100 \mu \mathrm{g} / \mathrm{ml})$ at $37^{\circ} \mathrm{C}$ with $5 \% \mathrm{CO} 2$ in humidified environment. For all transfections studies, cells were maintained without antibiotics.

\section{Mice}

Mice (BALB/c) of different age group i.e. infants, 2 months old and 4-5 week old females were procured from the animal house facility of National Institute of Virology, Pune, India. All animals were maintained according to the guidelines of Committee of Protection, Supervision and Control of Experiments on Animals. The project was approved by Indian GMO Research Information System (IGMORIS) and Institutional Biosafety Committee (IBSC).

\section{Cloning}

Plasmid used in the study was pAcGFP1-N1 (Clonetech, Takara). For the construction of (pCMV-E) construct, JEV propagated from tissue culture fluid of PS cells was used for RNA isolation (Trizol reagent, Invitrogen). The fragment of 2047 bp of partial C, prM and E gene [GenBank: EU372660] was amplified with Forward primer: 5'GGTACCATGTGGCTCGAGAGCTTG-3' and Reverse primer: 5'-GGATCCTTTATTAAGCATGGACATTGG TCGCTA-3' employing Reverse Transcriptase PCR, using MMLV-RT and Platinum Taq. Start and stop codon (underlined) were included in forward and reverse primer respectively. Amplicon after cloning in pGEM $^{\circledR}$ - T Easy cloning vector (Promega Corporation, Madison, USA) was excised using EcoRI restriction enzyme and cloned in EcoRI digested pAcGFP1-N1 expression vector. For (pMS-E), macrosialin promoter [GenBank: AF039399], was amplified with Forward primer: 5'-TATTAATGACCAAATCTACAGGGAGAACCC-3' and Reverse primer: 5'-AGCGCTAGATGCTCAGACCAGCTA-3' with VspI/ Eco47III incorporated (underlined) and cloned in StrataClone $^{\mathrm{TM}}$ PCR Cloning kit (Stratagene, USA). After digestion with VspI/Eco47III it was subcloned in similar digested pCMV-E construct and ligated. Devoid of promoter a negative control vector (pNIX-E) was constructed as described elsewhere [38]. Orientation and codon in-frame for all reconstructed clones were confirmed through restriction analysis (Figure 1) and sequencing.

Purified plasmids were prepared using EndoFree ${ }^{\circledR}$ Plasmid Maxi Kit (Qiagen, Germany), according to manufacturer's instruction. The quality of plasmid was assessed using Nanodrop by light absorption at 260/280 $\mathrm{nm}$ ratio and by $1 \%$ agarose gel electrophoresis. All the plasmids were dissolved in sterile PBS for in vivo studies and nuclease free water for ex vivo studies.

\section{Western blot}

Transfection was carried out with different constructs encoding E protein of JEV using Lipofectamine ${ }^{\mathrm{TM}} 2000$
(Invitrogen, USA) with $2 \mu \mathrm{g}$ of DNA as per manufacturer's instruction. Analysis for the blot was performed with $50 \mu \mathrm{g}$ of cell lysate from RAW 264.7 cells. After 24 hours of transfection, cells were harvested, washed, mixed with an equal volume of $2 \times$ loading buffer and boiled for 10 min. Proteins were separated onto a discontinuous SDS-polyacrylamide gel with 5\% stacking gel and 10\% resolving gel and transferred to a nitrocellulose membrane (Amersham Biosciences, USA). The membrane was blocked by $5 \%$ skimmed milk powder in PBS and incubated with anti JEV monoclonal antibody [47] followed by goat anti-mouse IgG-HRP conjugate (Sigma). Bands were developed with diaminobenzidine tetrahydrochloride$\mathrm{H}_{2} \mathrm{O}_{2}$ solution.

\section{Immunofluorescence assay}

RAW264.7 cells grown on coverslips were transfected with pCMV-E, pMS-E and pNIX-E for 24 hours. The cells were fixed with $4 \%$ paraformaldehyde for $10 \mathrm{~min}$ and blocked with 1\% BSA in PBS. The cells were permeabilized for detection of E protein, anti JEV monoclonal antibodies were used as primary antibody and probed with goat anti-mouse IgG FITC-conjugated Ab (Sigma, USA). The fluorescence was observed under confocal microscope.

\section{Mouse immunization and challenge experiments}

Immunization studies were carried out in female inbred BALB/c mice aged between 4-5 weeks. Animals were divided into groups of 14, each for the following constructs: pCMV-E, pMS-E, pNIX-E, pCMV-E/MbrAg and PBS. All constructs were suspended in PBS with concentration of 1 $\mu \mathrm{g} / \mu \mathrm{l}$ and antigen with $0.5 \mu \mathrm{g} / \mu \mathrm{l}$ with $100 \mu \mathrm{l}$ inoculated. Mice were anesthesised and injected through i.m. route with $50 \mu \mathrm{l}$ of constructs in both left and right quadriceps muscle. Animals in each group were given booster injection with the same concentration after 3 weeks of primary immunization and the next booster after 2 weeks. In pCMV-E/JE-MbrAg group, DNA construct followed by MbrAg as boosters were inoculated. After 7 weeks of immunization, all mice were challenged with lethal dose of JEV strain $733913\left(100 \mathrm{LD}_{50}\right)$ through i.p. route followed by $1 \%$ starch by the i.c. route in order to breach the blood brain barrier [49]. These mice were observed for mortality for 6 weeks after challenge. Sera samples were collected by capillary through orbital sinus bleeding method at different time points and antibody response were assessed. To determine the $50 \%$ lethal dose $\left(\mathrm{LD}_{50}\right)$ beforehand, groups of 11-12 weeks old mice were injected with i.p./i.c. starch route with 10 fold serial dilutions of virus.

\section{Enzyme Linked Immunosorbent Assay (ELISA)}

Standard protocols for ELISA were used. Briefly, tissue culture derived JEV Ag $(1 \mu \mathrm{g})$ was coated overnight in 


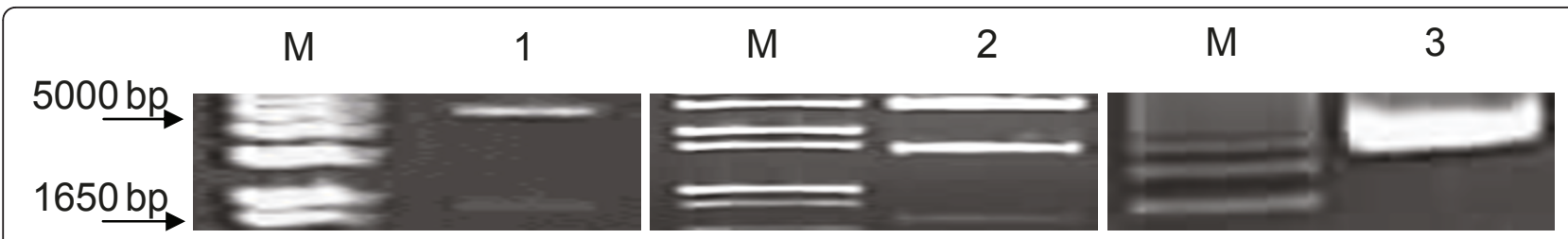

Figure 1 Restriction analysis of the constructs. Independent run gel documented in 1\% Agarose in TAE buffer. M: 1 Kb+ Ladder (Invitrogen); 1: pCMV-E with Sacl digested (Fragments: 4999 \& 1812 bp); 2: pMS-E with Vspl + Notl digested (Fragments: 2926 + 1551 + 703 bp); 3: pNIX-E (Undigested).

$50 \mu \mathrm{l}$ of carbonate buffer. After blocking with $1 \%$ BSA in PBS, $100 \mu \mathrm{l}$ of diluted mouse serum was added per well and incubated for $1 \mathrm{hr}$. After washing with PBST (PBS with $0.1 \%$ Tween 20), $100 \mu \mathrm{l}$ of goat anti-mouse IgGHRP conjugate (1:5000, Sigma) was added in each well. The colour was developed using the substrate orthophenyl-diamine (OPD) solution. The reaction was stopped with $100 \mu \mathrm{l}$ of $4 \mathrm{~N} \mathrm{H}_{2} \mathrm{SO}_{4}$. The absorbance was measured at $490 \mathrm{~nm}$ on a microplate reader (680 XR Microplate Reader). The end point titres of antibodies were determined as the reciprocal of highest dilution that gave an absorbance two times higher than that of nonimmune serum.

\section{Neutralization Assay}

The virus neutralization assay was performed to assess the ability of produced antibody to neutralize the live JEV. As a positive serum JEV immune peritoneal fluid was used. The test was carried out with pooled mice sera of each group (pCMV-E, pMS-E, pNIX-E, pCMV-E/MbrAg and PBS) collected at day $0,21,36$ and 51 before booster immunizations and complement inactivated. PS cells were seeded in 96 well plate with a density of $2 \times 10^{5}$ cells $/ \mathrm{ml}$ in MEM supplemented with 10\% FBS and incubated overnight. Fivefold serial dilution (1:10 to 1:1250) of serum along with controls was carried out in round bottomed microtitre plate (Nunc) and mixed with equal volume $(60 \mu \mathrm{l})$ of $100 \mathrm{TCID}_{50}$ of tissue culture pool of virus in MEM with $5 \%$ FCS. After incubation at $37^{\circ} \mathrm{C}$ for $1 \mathrm{hr}$, $100 \mu \mathrm{l}$ of this antibody virus mixture was added to the preformed monolayer of cells and incubated for 3 days. Virus titration for determining the dose was challenge virus, incorporated in each plate. NT titre was expressed as reciprocal of serum dilution that resulted in more than $50 \%$ CPE [50].

\section{Cytokine profiling}

Three weeks after the last immunization, splenocytes were harvested and resuspended at $2 \times 10^{5}$ cells $/ \mathrm{ml}$ in RPMI 1640 (Gibco, USA) supplemented with 10\% FBS (Gibco, USA) penicillin $(100 \mathrm{IU} / \mathrm{ml})$ and streptomycin $(100 \mu \mathrm{g} / \mathrm{ml})$. Each well of 24 well plate contained $4 \times$ $10^{5}$ cells in triplicate for each group. JE antigen $(10 \mu \mathrm{g})$ was added to each well. As a positive control Con A (Sigma, USA) was used. After 72 hours of incubation at $37^{\circ} \mathrm{C}$ in $5 \% \mathrm{CO}_{2}$ the supernatant was collected and centrifuged to remove the cell debris. That supernatant was stored in $-70^{\circ} \mathrm{C}$ till tested.

The evaluation of Th1 and Th2 cytokine was performed by Cytometric Bead Array (CBA) (BD Biosciences) as per manufacturer's instruction. Briefly $50 \mu \mathrm{l}$ of bead was mixed with the supernatant along with the given standards and incubated for 2 hours at RT in dark. The beads were washed and resuspended in $300 \mu \mathrm{l}$ of wash buffer. The BD FACSAria ${ }^{\mathrm{TM}} \mathrm{II}$ instrument was then setup using BD FACSComp software and setup beads. Following acquisition the cytokine concentration was determined using the standard curve prepared.

\section{Lymphocyte proliferation assay}

The assay was performed using tritiated thymidine incorporation as previously described [48]. Splenocytes were harvested from all the groups and resuspended at $2 \times 10^{5}$ cells/well in 96 well flat bottomed plate (Nunc). Cells were grown in RPMI 1640 (Gibco, USA) supplemented with $10 \%$ FBS with antibiotics and pulsed overnight with JEV antigen. Con A (Sigma, USA) was used as positive control. The assay was done in triplicates using three different concentrations. After 3 days the cells were pulsed with $1 \mu \mathrm{Ci}$ $\left[{ }^{3} \mathrm{H}\right]$ thymidine (BRIT) for $18 \mathrm{~h}$. Cells were harvested onto GF/C (Whatman) filter disc and thymidine incorporation was measured with beta liquid scintillation counter (Tri$\mathrm{Carb}^{\circledR}$, PerkinElmer), as cpm. Data were represented as proliferation indices, calculated as: (Thymidine incorporated by cells in the presence of $E$ protein/Thymidine incorporated in the absence of $\mathrm{E}$ protein)

\section{Statistical analysis}

All of the test data were analyzed with PASW Statistics (version 18.0). Data were considered to be statistically significant when $\mathrm{P}<0.05$

\section{Results}

\section{Western Blot Analysis}

After 24 hours of transfection similar amount of cell lysate were subjected to SDS-PAGE (Figure 2A) and 


Figure 2 Western Blot Analysis. (A) 10\% SDS-PAGE gel (B) Western blot analysis of the total cell lysates of the RAW 264.7 cells. M: PageRulerTM
(Fermentas); 1: pCMV-E; 2: pMS-E; 3: pNIX-E. The blot shows expressed prM and E protein from different constructs after 24 hours of transfection.

Western blot analysis in all the wells. The monoclonal antibody against $\mathrm{E}$ protein reacted specifically with $\mathrm{E}$ protein of $\sim 54$ and prM of $20 \mathrm{kDa}$ (Figure 2B, 1, 2). No visible band was observed in the lane of non transfected cells (Figure 2B, 3) indicative of absence of $\mathrm{E}$ and prM protein in the sample.

\section{Immunofluorescence assay}

After the transfection, immunofluorescence analysis showed the green fluorescent cells which represented the expression of E gene of JEV (Figure 3A-B). No such signal was detected in the cells transfected with pNIX-E or untransfectd cells (Figure 3C-D).

\section{Mouse challenge experiments}

Post immunization, no visible side effects were observed in the mice due to any of the construct used. To study the potency of vaccine, the immunized mice were challenged with lethal dose $\left(100 \mathrm{LD}_{50}\right)$ of JEV by previously reported method [48]. As JEV is not pathogenic by intra peritoneal (i.p.) route, following virus administration by i.p. route, blood brain barrier is breached by administration of $1 \%$ starch by intra cranial (i.c.) route. The mice were observed for mortality for 6 weeks post challenge.

Table 1 depicts that the mice immunized with pCMVE shows $87.5 \%$ protection against lethal challenge of JEV. The newly constructed vaccine pMS-E was effective enough to give $75 \%$ protection. None of the mice survived after challenge from the negative control group pNIX-E and PBS. Significant level of difference was observed in groups of pCMV-E, pMS-E and pCMV-E/ MbrAg in comparison to pNIX-E or PBS groups.

\section{ELISA}

Antibody response was observed after immunization with different constructs through ELISA. Serum samples were collected from mice before every immunization and two weeks after the last immunization. Pooled sera were analyzed for the entire group in triplicate. The highest $\mathrm{Ab}$ titre was observed for the $\mathrm{pCMV}-\mathrm{E} / \mathrm{MbrAg}$ group, followed by pCMV-E and pMS-E, whereas only basal level of titre was obtained in pNIX-E and PBS inoculated mice. There were no significant differences $(p>0.05)$ in the Ab titre of all the groups in day zero and after the first dose, however significant increase in $\mathrm{Ab}$ titre after the second dose was observed in (pCMV$\mathrm{E}$, pMS-E and pCMV-E/MbrAg) groups which further increased after the next booster (Figure 4).

\section{Virus neutralization assay}

The virus neutralization test was performed to evaluate the ability of the constructs to elicit a neutralizing $\mathrm{Ab}$ response. Serum from the vaccinated groups showed considerable titres of JEV neutralizing Ab. Virus neutralizing $\mathrm{Ab}$ titres was observed to be 1:500 for the pCMVE/MbrAg group, whereas for pCMV-E group it was

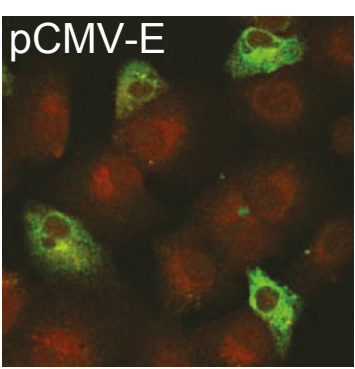

A

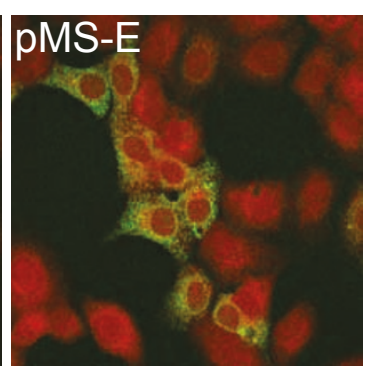

B

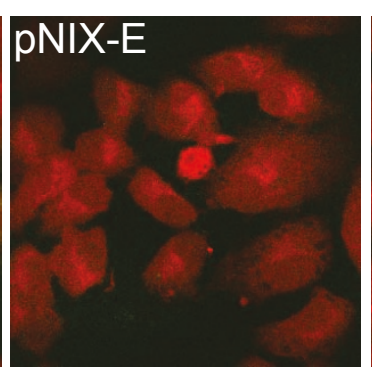

C

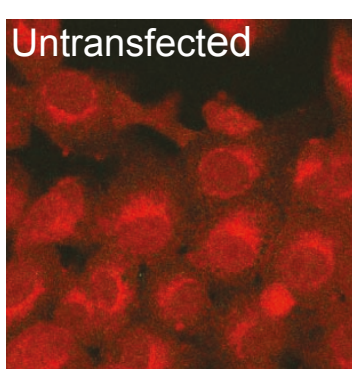

D

Figure 3 Detection of E protein using IFA. Expression of E protein in transfected RAW264.7 cells were detected 24 hrs post transfection. Figures (A) pCMV-E and (B) pMS-E confirms the expression of E protein whereas Fig. (C) pNIX-E and (D) Untransfected were used as a negative control. 
Table 1 Protection of mice challenged with lethal dose of Japanese encephalitis virus (strain 733913)

\begin{tabular}{llll}
\hline Plasmid Constructs & Number of mice challenged & Number of mice surviving & Protection (\%) \\
\hline pCMV-E & 8 & 7 & 87.5 \\
pMS-E & 8 & 6 & 75 \\
pCMV-E/MbrAg & 8 & 7 & 87.5 \\
pNIX-E & 8 & 0 & 0 \\
PBS & 8 & 0 & 0 \\
\hline
\end{tabular}

1:450. The newly constructed vaccine induced the $\mathrm{Ab}$ titre at 1:300 (Figure 5). This difference was consistent for the group and reproducible. No such neutralization $\mathrm{Ab}$ activity was observed for pNIX-E and PBS inoculated group.

\section{Cytokine profiling}

To characterize the immune response in different vaccinated groups, splenocytes were isolated after immunization protocol and the responses of T-cells were evaluated using mouse Th1/Th2 CBA system. This allowed simultaneous measurement of Th1 (IL-2, IFN- $\gamma$ and TNF- $\alpha$ ) and Th2 cytokines (IL-4 and IL-5) in antigen stimulated Tcells supernatant. After immunization in APC promoter group Th1 cytokines were notably high, while Th2 cytokines increased moderately. We observed significant increase in the cytokine levels compared to the pre-bleed level for any of the group. The level of cytokine was significantly higher in pCMV-E, pMS-E, pCMV-E/MbrAg immunized mice in comparison to the groups inoculated with pNIX-E and PBS. Hence the immune response was skewed towards Th1 type and only moderate towards Th2 (Figure 6).

\section{Lymphocyte proliferation assay}

The ability of splenocytes to proliferate when stimulated with the JEV Ag was analyzed through lymphocyte proliferation assay. We observed a significant increase in proliferation for pCMV-E, pMS-E, pCMV-E/MbrAg immunized mice in comparison to the pNIX-E and PBS inoculated groups (Figure 7). The response in proliferation increased on increasing the concentration of Ag upto $20 \mu \mathrm{g}$. Spleen from two mice per group was used for the assay.

\section{Discussion}

Immune system has devised modalities to overcome nonspecific, autoreactive immune response while optimally maintaining the balance. Thus, immune response through antigen presentation by non-hematopoitic cells would actually be downregulated, while immune response generated through professional APC would be long term and balanced. Failure to have second signalling, which lack in non professional APC may lead to reduced immune response or even anergy [51]. The promoter of CMV is commonly used in mammalian expression system due to its strong activity in large varieties of cells [52]. The

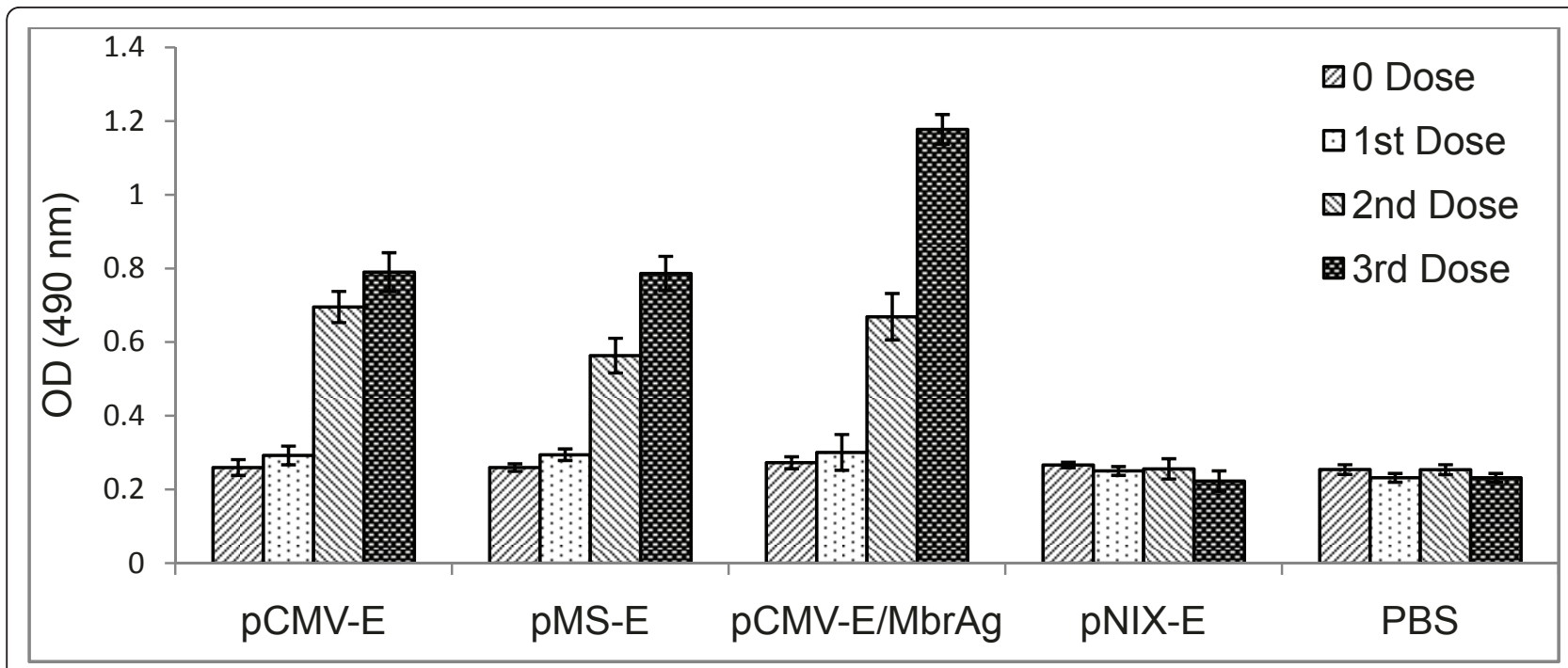

Figure 4 ELISA. Antibody response of BALB/C mice immunized with plasmid DNA of different constructs by intramuscular injection. First booster dose was given after 21 days of first immunization and second booster after 36 days. Serum samples were collected on the given days and stored at -70 . Each column indicates the mean response \pm SEM. 


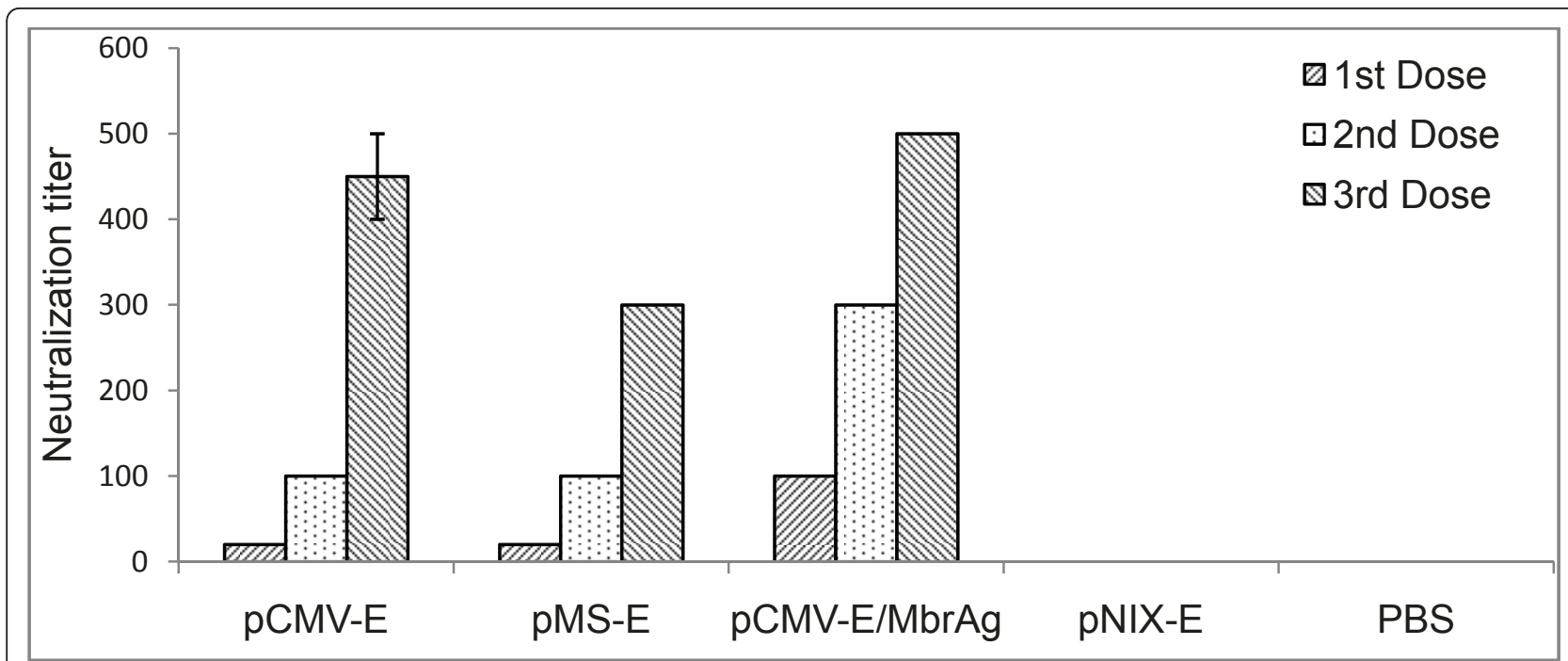

Figure 5 Virus neutralization assay. Neutralization assay of sera from mice immunized with different constructs. The highest dilution of mice sera that resulted into more than 50\% CPE was considered. As a positive control JEV immune peritoneal fluid was used whereas peritoneal fluid from the non immunized mice was used as a negative control.

preference of gene expression is based on its application; in gene therapy constitutive expression is favoured [53]. On the contrary, to enhance the immune response of DNA vaccine, gene expression was restricted only to professional APC [54] and sometimes limited as a safety concern [55]. DC is considered to be the most potent and remained as highly preferred target cell. Although in a study, targeting DC alone was reported insufficient [35].

After ex vivo evaluation of promoters active in macrophages [38], we have selected the highest expressing constructs (macrosialin) and extended our study for in vivo analysis of macrosialin along with CMV promoter for comparison. JEV E protein expressed under these promoters was used for evaluation of concept in terms of antigen specific immune response. Induction of virus neutralizing antibodies, protection from lethal challenge and cytokine profile of immune splenocytes was studied and compared. E protein of JEV is considered to be a vital protein to target, because antibody against $\mathrm{E}$ protein has shown to neutralize JEV infectivity and also it is functionally important $[12,56]$.

All the plasmid constructs were tested and confirmed to drive the expression of $\mathrm{E}$ gene of JEV before in vivo inoculation. In transfection experiment, Western blot and IFA analysis showed the constructs under study expressed E gene with high efficiency in RAW 264.7 cells. This indicated that the plasmid could be used further for subsequent in vivo experiments. Though we have shown the expression of E protein in RAW264.7 cells as a qualitative test, still the noticeably higher expression is seen with pCMV-E construct. We had shown similar results quantitatively in our earlier study using GFP reporter system [38].

To explore the applicability of these constructs as vaccine, groups of mice were vaccinated intramuscularly with recombinant plasmids. In addition, to evaluate prime boost models, administration of plasmid followed by MbrAg as a booster was used. All constructs, pCMVE, pMS-E and pCMV-E/MbrAg (test groups) successfully led to the production of anti-E Ab. As measured by ELISA, the Ab produced in PCMV-E and pMS-E were nearly similar after the third dose, but increased significantly in pCMV-E/MbrAg groups. To measure the neutralizing abilities of these $\mathrm{Ab}$, virus neutralization test was carried out. pCMV-E/MbrAg group showed the highest neutralizing Ab titre in all sera, whereas pCMV$\mathrm{E}$ and pMS-E showed similar titre after the second dose, after the third dose the neutralizing Ab titre increased significantly in pCMV-E groups. The increase in Ab titre after subsequent dose shown by ELISA and neutralizing test was similar in comparison shown by other group (21).

For the evaluation of cellular response, lymphocyte proliferation assay was carried out. Significant proliferative response was observed in the splenocytes of vaccinated mice when compared with either pNIX-E or PBS inoculated mice. Similar proliferation indices were seen in the group of pCMV-E and pMS-E, whereas pCMV-E/ MbrAg showed the highest response.

Cytokine has a major role to play in immune response against viruses, through direct antiviral activity as well as directing an array of immune responses to control 

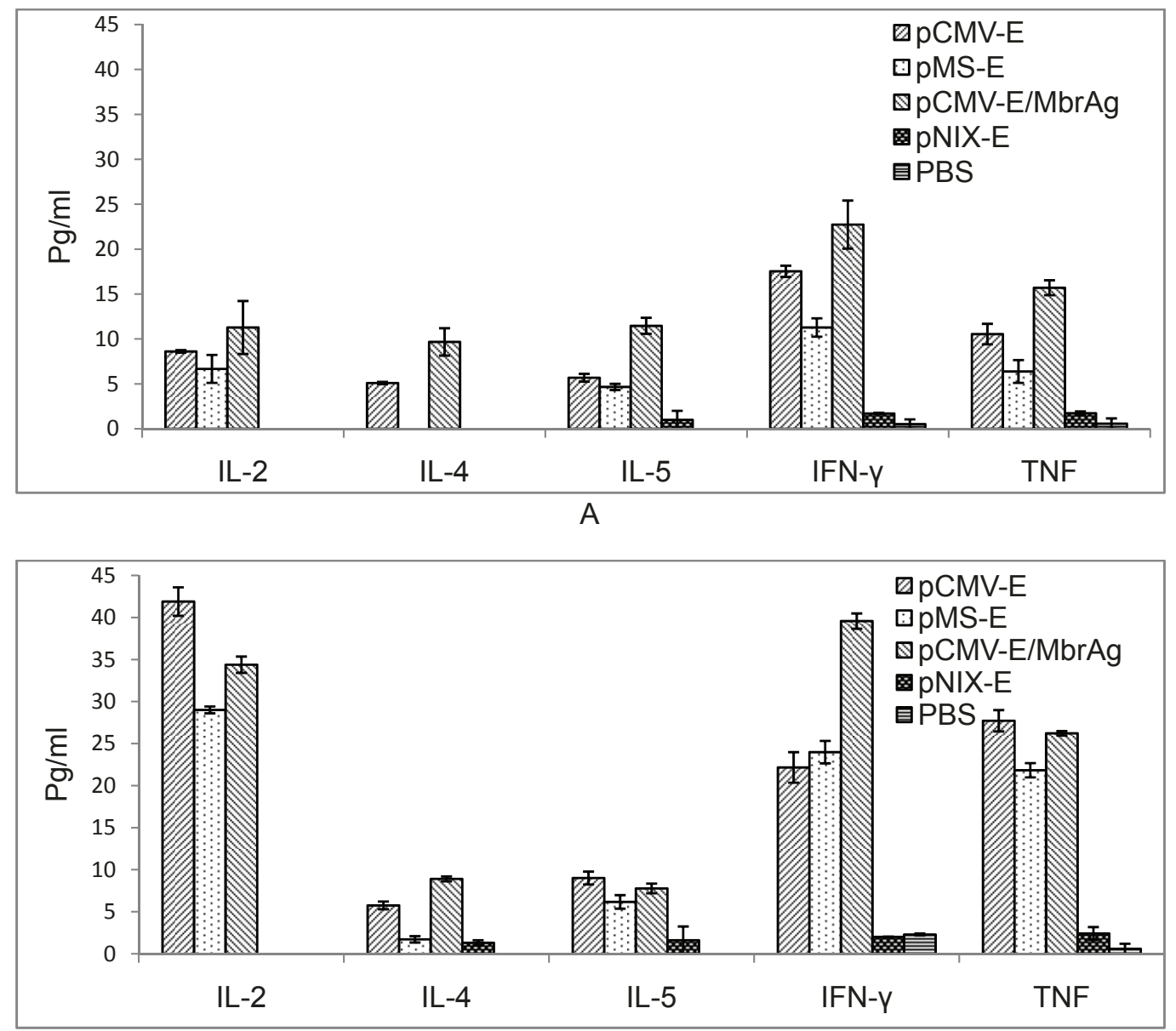

B

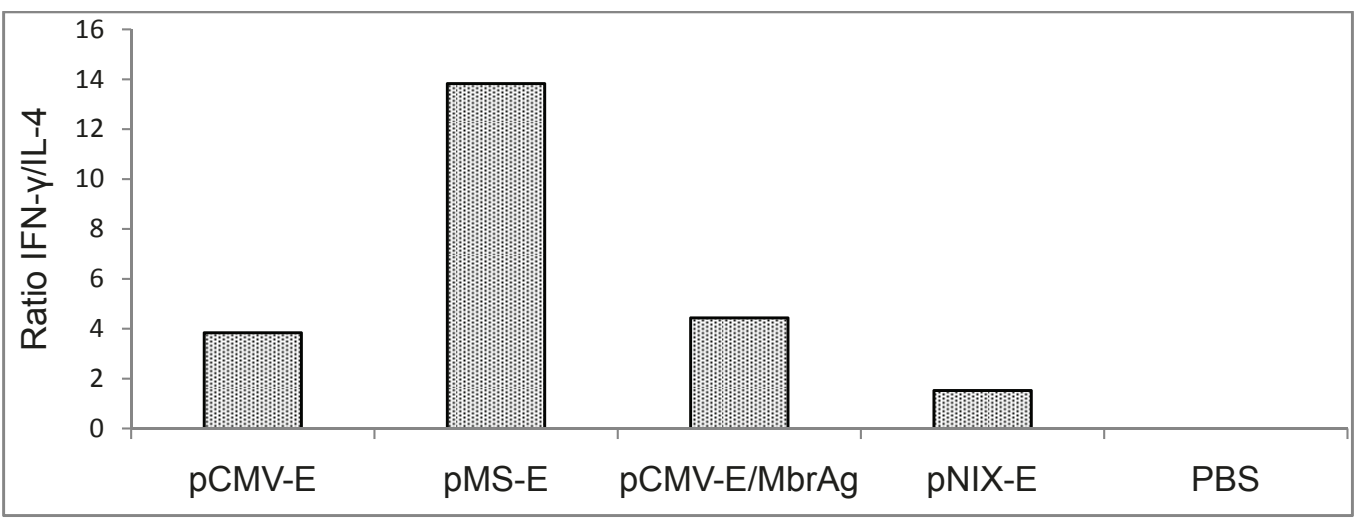

C

Figure 6 Production of cytokines upon immunization of different constructs. CBA was performed with the supernatant for Th1 and Th2 cytokines. The graph represents the concentration of cytokines TNF, IFN- $\gamma, I L-2, I L-4$ and IL-5. The data presented here are the means \pm SEM of cytokine profile after (A) Second dose, (B) third dose and (C) the ratio of IFN- $\gamma$ and IL-4 to show the skewness of immune response.

the infection [57]. We studied the responses after immunization governed by different promoters through cytokine secretion profile of spleen cells. The result indicated that the magnitude of cytokine production was higher in pCMV-E in comparison to pMS-E at all times. The cytokine level for $\mathrm{pCMV-E/MbrAg} \mathrm{group} \mathrm{increased}$ dramatically after the second dose since it was boosted by MbrAg which acted as a better immunogen. This 


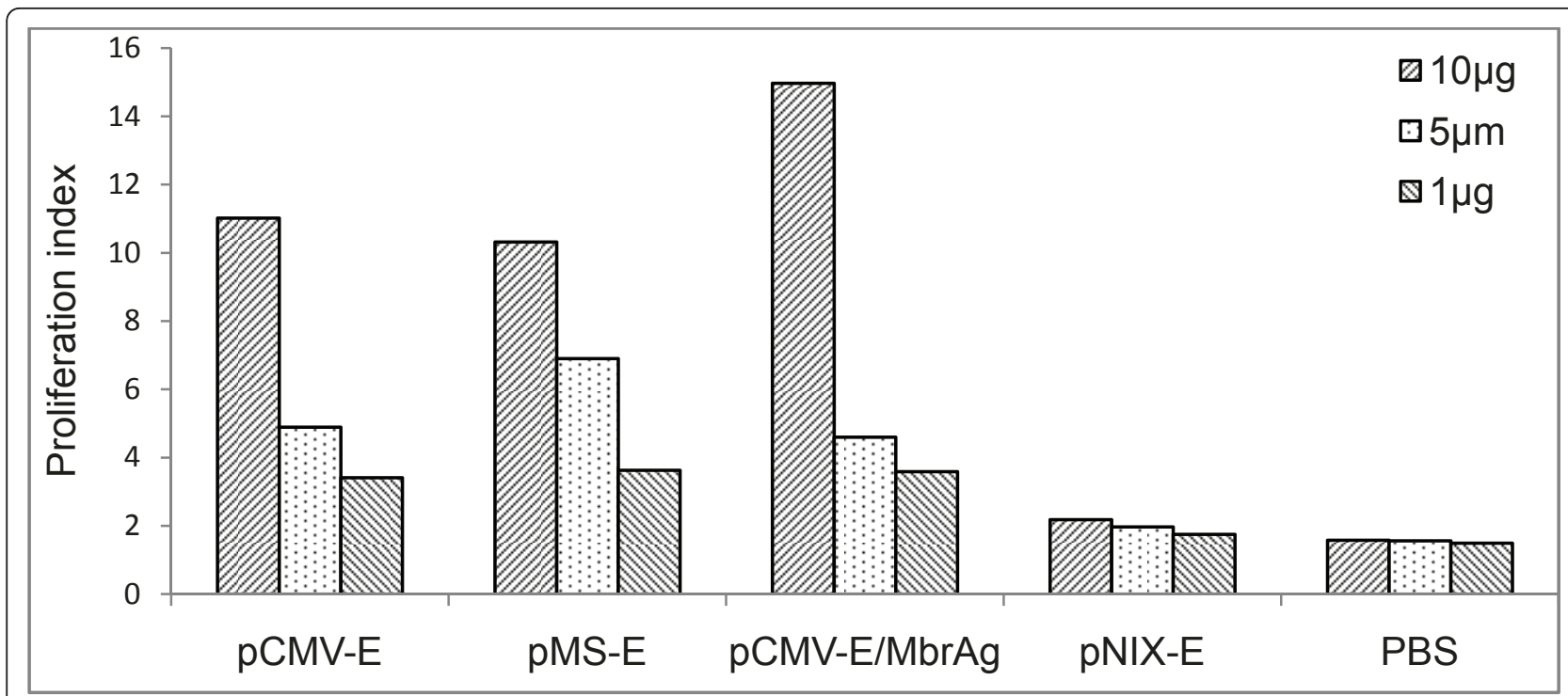

Figure 7 Lymphocytes proliferation assay. Lymphocytes from mice group immunized with different vaccine constructs were incubated with various amount of JEV Ag. After each dose the proliferative response was evaluated. Lymphocytes from unimmunized and pNIX-E were used as negative controls. Proliferation index were calculated from the means of experiments in triplicate.

finding is consistent with previous studies which have demonstrated that DNA priming followed by protein boosting results in greater humoral response and mixed Th1/Th2 response with higher IFN- $\gamma$, IL- 2 and IL-4 cytokines [58,59]. After the third dose increase in Th1 cytokine might have downregulated the Th2 cytokines. To evaluate the ratio of Th1 and Th2 responses, we observed the ratio of IFN- $\gamma / \mathrm{IL}-4$, interestingly we observed macrosialin promoter highly skewed the response towards Th1 cytokine in comparison to CMV promoter. Our result for dominant Th1 response after i. $\mathrm{m}$. inoculation of plasmid is in agreement with the earlier observation [21], moreover it also supports the previously observed Th1 biased response with APC targeted Ag delivery $[54,60,61]$.

To assess the efficacy of vaccine in terms of protection, mice were challenged with lethal dose of JEV. We observed $87.5 \%$ protection in PCMV-E group and also for pCMV-E/MbrAg group, whereas it was $75 \%$ in pMSE group. For protection to the host against JEV, neutralizing Ab plays a significant role [20]. For viral infections the importance of IFN- $\gamma$ has been amply demonstrated [57]. Comparatively lower level of protection in pMS-E could be attributed to lower neutralizing Ab titre and lower IFN- $\gamma$ levels (after second dose) and its non significant rise after the third dose. TNF is a proinflamatory cytokine considered efficient in stimulating DC maturation, migration and induction of proliferative and cytolytic activity of T cells and NK cells [62], for pMS-E lower TNF level was observed in comparison to pCMV-E or pCMV-E/MbrAg. With the acceptable difference in overall immune response in the constructs, it is considered as evidence of protection if the neutralizing titres are $\geq 1: 10$ [63].

In conclusion, $\mathrm{CMV}$ and Macrophage active promoter constructs resulted in successful expression of the $\mathrm{E}$ protein after intramuscular (i.m.) immunization. The expression level of pMS-E was lower than those obtained with the use of pCMV-E constructs but sufficient to induce protection in mouse model.

\section{Conclusions}

In summary, we have demonstrated herein the ex vivo expression of E protein directed by CMV and Macrophage active promoter. When compared its activity in terms of immunity in mice model, response of pMS-E was lower than those obtained with the use of pCMV-E constructs but sufficient to induce protection in mouse model. With further study the use of macrosialin promoter could be an interesting alternative to the use of ubiquitous promoter, especially for the treatment of pathogen requiring dominant cellular immune response such as viral or anti-cancer vaccine.

\section{Acknowledgements}

Ahsan MF acknowledges Indian Council of Medical Research, Government of India, for providing Senior Research Fellowship (SRF) and National Institute of Virology, Pune, for the extended fellowship. We thankfully acknowledge Dr. Bondre VP, Dr. Sapkal GN for their support and Mr. Walimbe AM for his help in statistical analysis of the data. We gratefully appreciate the intellectual discussion with Dr. Satyendra K. We owe our thanks to Mr. Janardhan V, Mr. Sonawane VA, Mr. Ayachit VM, Mr. Manish S, Ms. Gupte G, Dr. Kulkarni M and Mr. Nabendu B for their help during the study. We also 
thank Mr. Roopesh, Ms. Reshma, Ms. Daya, Ms. Harini, Dr. Santosh K and Mr. Ayachit VM.

\section{Authors' contributions}

MFA has planned, designed and carried out all the experiments. MMG envisioned and supervised all the studies. Both the authors read and approved the final manuscript.

\section{Competing interests}

The authors declare that they have no competing interests.

Received: 21 March 2011 Accepted: 2 August 2011

Published: 2 August 2011

\section{References}

1. van den Hurk AF, Ritchie SA, Mackenzie JS: Ecology and geographical expansion of Japanese encephalitis virus. Annu Rev Entomol 2009, 54:17-35.

2. Erlanger TE, Weiss S, Keiser J, Utzinger J, Wiedenmayer K: Past, present, and future of Japanese encephalitis. Emerg Infect Dis 2009, 15(1):1-7.

3. Mackenzie JS, Gubler DJ, Petersen LR: Emerging flaviviruses: the spread and resurgence of Japanese encephalitis, West Nile and dengue viruses. Nat Med 2004, 10(12 Suppl):S98-109.

4. Solomon T: Control of Japanese encephalitis-within our grasp? N Engl J Med 2006, 355(9):869-871.

5. Solomon $T$, Thao $T$, Lewthwaite $P$, Ooi $M H$, Kneen $R$, Dung NM, White $N$ : A cohort study to assess the new WHO Japanese encephalitis surveillance standards. Bull World Health Organ 2008, 86(3):178-186.

6. Torresi J, McCarthy K, Feroldi E, Méric C: Immunogenicity, safety and tolerability in adults of a new single-dose, live-attenuated vaccine against Japanese encephalitis: Randomised controlled phase 3 trials. Vaccine 2010, 28(50):7993-8000.

7. Nothdurft HD, Jelinek T, Marschang A, Maiwald H, Kapaun A, Löscher T: Adverse reactions to Japanese encephalitis vaccine in travellers. $J$ Infect 1996, 32(2):119-122.

8. Plesner AM, Rønne T: Allergic mucocutaneous reactions to Japanese encephalitis vaccine. Vaccine 1997, 15(11):1239-1243.

9. Hasan UA, Abai AM, Harper DR, Wren BW, Morrow WJ: Nucleic acid immunization: concepts and techniques associated with third generation vaccines. J Immunol Methods 1999, 229(1-2):1-22.

10. Chambers TJ, Hahn CS, Galler R, Rice CM: Flavivirus genome organization, expression, and replication. Annu Rev Microbiol 1990, 44:649-688.

11. Sumiyoshi H, Mori C, Fuke I, Morita K, Kuhara S, Kondou J, Kikuchi Y, Nagamatu H, Igarashi A: Complete nucleotide sequence of the Japanese encephalitis virus genome RNA. Virology 1987, 161(2):497-510.

12. McMinn PC: The molecular basis of virulence of the encephalitogenic flaviviruses. J Gen Virol 1997, 78(Pt 11):2711-2722.

13. Kimura-Kuroda J, Yasui K: Protection of mice against Japanese encephalitis virus by passive administration with monoclonal antibodies. J Immunol 1988, 141(10):3606-3610.

14. Konishi E, Mason PW: Proper maturation of the Japanese encephalitis virus envelope glycoprotein requires cosynthesis with the premembrane protein. J Virol 1993, 67(3):1672-1675.

15. Konishi E, Pincus S, Paoletti E, Shope RE, Burrage T, Mason PW: Mice immunized with a subviral particle containing the Japanese encephalitis virus prM/M and $\mathrm{E}$ proteins are protected from lethal JEV infection. Virology 1992, 188(2):714-720.

16. Chen HW, Pan CH, Liau MY, Jou R, Tsai CJ, Wu HJ, Lin YL, Tao MH: Screening of protective antigens of Japanese encephalitis virus by DNA immunization: a comparative study with conventional viral vaccines. J Virol 1999, 73(12):10137-10145.

17. Ashok MS, Rangarajan PN: Protective efficacy of a plasmid DNA encoding Japanese encephalitis virus envelope protein fused to tissue plasminogen activator signal sequences: studies in a murine intracerebral virus challenge model. Vaccine 2002, 20(1112):1563-1570

18. Ashok MS, Rangarajan PN: Immunization with plasmid DNA encoding the envelope glycoprotein of Japanese Encephalitis virus confers significant protection against intracerebral viral challenge without inducing detectable antiviral antibodies. Vaccine 1999, 18(1-2):68-75.
19. Chang GJ, Hunt AR, Davis B: A single intramuscular injection of recombinant plasmid DNA induces protective immunity and prevents Japanese encephalitis in mice. J Virol 2000, 74(9):4244-4252.

20. Konishi E, Yamaoka M, Khin-Sane-Win, Kurane I, Takada K, Mason PW: The anamnestic neutralizing antibody response is critical for protection of mice from challenge following vaccination with a plasmid encoding the Japanese encephalitis virus premembrane and envelope genes. J Virol 1999, 73(7):5527-5534.

21. Kaur R, Sachdeva G, Vrati S: Plasmid DNA immunization against Japanese encephalitis virus: immunogenicity of membrane-anchored and secretory envelope protein. J Infect Dis 2002, 185(1):1-12.

22. Ishii N, Fukushima J, Kaneko T, Okada E, Tani K, Tanaka SI, Hamajima K Xin KQ, Kawamoto S, Koff W, Nishioka K, Yasuda T, Okuda K: Cationic liposomes are a strong adjuvant for a DNA vaccine of human immunodeficiency virus type 1. AIDS Res Hum Retroviruses 1997, 13(16):1421-1428.

23. Sato $Y$, Roman $M$, Tighe $H$, Lee $D$, Corr M, Nguyen MD, Silverman GJ, Lotz M, Carson DA, Raz E: Immunostimulatory DNA sequences necessary for effective intradermal gene immunization. Science 1996, 273(5273):352-354

24. Iwasaki A, Stiernholm BJ, Chan AK, Berinstein NL, Barber BH: Enhanced CTL responses mediated by plasmid DNA immunogens encoding costimulatory molecules and cytokines. J Immunol 1997, 158(10):4591-4601

25. Okada E, Sasaki S, Ishii N, Aoki I, Yasuda T, Nishioka K, Fukushima J, Miyazaki J, Wahren B, Okuda K: Intranasal immunization of a DNA vaccine with IL-12- and granulocyte-macrophage colony-stimulating factor (GMCSF)-expressing plasmids in liposomes induces strong mucosal and cell-mediated immune responses against HIV-1 antigens. J Immunol 1997, 159(7):3638-3647

26. Sha Z, Vincent MJ, Compans RW: Enhancement of mucosal immune responses to the influenza virus $\mathrm{HA}$ protein by alternative approaches to DNA immunization. Immunobiology 1999, 200(1):21-30

27. Livingston JB, Lu S, Robinson $\mathrm{H}$, Anderson DJ: Immunization of the female genital tract with a DNA-based vaccine. Infect Immun 1998, 66(1):322-329.

28. Tuting T, Storkus WJ, Falo LD Jr: DNA immunization targeting the skin: Molecular control of adaptive immunity. J Invest Dermatol 1998, 111(2):183-188.

29. Ji H, Wang TL, Chen CH, Pai SI, Hung CF, Lin KY, Kurman RJ, Pardoll DM, Wu TC: Targeting human papillomavirus type $16 \mathrm{E7}$ to the endosomal/ lysosomal compartment enhances the antitumor immunity of DNA vaccines against murine human papillomavirus type 16 E7-expressing tumors. Hum Gene Ther 1999, 10(17):2727-2740.

30. Ni J, Nolte B, Arnold A, Fournier P, Schirrmacher V: Targeting anti-tumor DNA vaccines to dendritic cells via a short CD11c promoter sequence. Vaccine 2009, 27(40):5480-5487.

31. Bonkobara M, Zukas PK, Shikano S, Nakamura S, Cruz PD Jr, Ariizumi K Epidermal Langerhans cell-targeted gene expression by a dectin-2 promoter. J Immunol 2001, 167(12):6893-6900.

32. Lori F, Kelly LM, Lisziewicz J: APC-targeted immunization for the treatment of HIV-1. Expert Rev Vaccines 2004, 3(4 Suppl):S189-198

33. Kimura T, Koya RC, Anselmi L, Sternini C, Wang HJ, Comin-Anduix B, Prins RM, Faure-Kumar E, Rozengurt N, Cui Y, Kasahara N, Stripecke R: Lentiviral vectors with $\mathrm{CMV}$ or $\mathrm{MHCll}$ promoters administered in vivo: immune reactivity versus persistence of expression. Mol Ther 2007, 15(7):1390-1399.

34. Hon H, Oran A, Brocker $T$, Jacob J: B lymphocytes participate in crosspresentation of antigen following gene gun vaccination. J Immunol 2005, 174(9):5233-5242

35. Lauterbach H, Gruber A, Ried C, Cheminay C, Brocker T: Insufficient APC capacities of dendritic cells in gene gun-mediated DNA vaccination. $J$ Immunol 2006, 176(8):4600-4607.

36. Pozzi LA, Maciaszek JW, Rock KL: Both dendritic cells and macrophages can stimulate naive CD8 T cells in vivo to proliferate, develop effector function, and differentiate into memory cells. J Immunol 2005, 175(4):2071-2081.

37. Kovacsovics-Bankowski M, Clark K, Benacerraf B, Rock KL: Efficient major histocompatibility complex class I presentation of exogenous antigen upon phagocytosis by macrophages. Proc Natl Acad Sci USA 1993, 90(11):4942-4946. 
38. Ahsan MF, Gore MM: Comparative analysis of macrophage associated vectors for use in genetic vaccine. Genet Vaccines Ther 2011, 9(1):10.

39. Li AC, Guidez FR, Collier JG, Glass CK: The macrosialin promoter directs high levels of transcriptional activity in macrophages dependent on combinatorial interactions between PU.1 and c-Jun. J Biol Chem 1998 273(9):5389-5399.

40. Rabinowitz SS, Gordon S: Macrosialin, a macrophage-restricted membrane sialoprotein differentially glycosylated in response to inflammatory stimuli. J Exp Med 1991, 174(4):827-836.

41. Holness CL, da Silva RP, Fawcett J, Gordon S, Simmons DL: Macrosialin, a mouse macrophage-restricted glycoprotein, is a member of the lamp/ Igp family. J Biol Chem 1993, 268(13):9661-9666.

42. O'Reilly D, Addley M, Quinn C, MacFarlane AJ, Gordon S, McKnight AJ, Greaves DR: Functional analysis of the murine Emr1 promoter identifies a novel purine-rich regulatory motif required for high-level gene expression in macrophages. Genomics 2004, 84(6):1030-1040.

43. Schaller E, Macfarlane AJ, Rupec RA, Gordon S, McKnight AJ, Pfeffer K: Inactivation of the F4/80 glycoprotein in the mouse germ line. Mol Cell Biol 2002, 22(22):8035-8043

44. McKnight AJ, Macfarlane AJ, Dri P, Turley L, Willis AC, Gordon S: Molecular cloning of $F 4 / 80$, a murine macrophage-restricted cell surface glycoprotein with homology to the G-protein-linked transmembrane 7 hormone receptor family. J Biol Chem 1996, 271(1):486-489.

45. Feng X, Teitelbaum SL, Quiroz ME, Cheng SL, Lai CF, Avioli LV, Ross FP: Sp1/Sp3 and PU.1 differentially regulate beta(5) integrin gene expression in macrophages and osteoblasts. J Biol Chem 2000, 275(12):8331-8340

46. Feng X, Teitelbaum SL, Quiroz ME, Towler DA, Ross FP: Cloning of the murine beta5 integrin subunit promoter. Identification of a novel sequence mediating granulocyte-macrophage colony-stimulating factordependent repression of beta5 integrin gene transcription. J Biol Chem 1999, 274(3):1366-1374.

47. Ghosh SN, Sathe PS, Sarthi SA, Cecilia D, Dandawate CN, Athawale SS, Pant U: Epitope analysis of strains of Japanese encephalitis virus by monoclonal antibodies. Indian J Med Res 1989, 89:368-375.

48. Biswas SM, Ayachit VM, Sapkal GN, Mahamuni SA, Gore MM: Japanese encephalitis virus produces a CD4+ Th2 response and associated immunoprotection in an adoptive-transfer murine model. $J$ Gen Virol 2009, 90(Pt 4):818-826.

49. Dewasthaly SS, Bhonde GS, Shankarraman V, Biswas SM, Ayachit VM, Gore MM: Chimeric T helper-B cell peptides induce protective response against Japanese encephalitis virus in mice. Protein Pept Lett 2007, 14(6):543-551.

50. Sapkal GN, Wairagkar NS, Ayachit VM, Bondre VP, Gore MM: Detection and isolation of Japanese encephalitis virus from blood clots collected during the acute phase of infection. Am J Trop Med Hyg 2007, 77(6):1139-1145

51. Felix NJ, Suri A, Salter-Cid L, Nadler SG, Gujrathi S, Corbo M, Aranda RL: Targeting lymphocyte co-stimulation: from bench to bedside. Autoimmunity 2010, 43(7):514-525.

52. Boshart M, Weber F, Jahn G, Dorsch-Häsler K, Fleckenstein B, Schaffner W: A very strong enhancer is located upstream of an immediate early gene of human cytomegalovirus. Cell 1985, 41(2):521-530.

53. Mizuguchi H, Xu ZL, Sakurai F, Mayumi T, Hayakawa T: Tight positive regulation of transgene expression by a single adenovirus vector containing the rtTA and tTS expression cassettes in separate genome regions. Hum Gene Ther 2003, 14(13):1265-1277.

54. Ross R, Sudowe S, Beisner J, Ross XL, Ludwig-Portugall I, Steitz J, Tüting T, Knop J, Reske-Kunz AB: Transcriptional targeting of dendritic cells for gene therapy using the promoter of the cytoskeletal protein fascin. Gene Ther 2003, 10(12):1035-1040.

55. Glenting J, Wessels S: Ensuring safety of DNA vaccines. Microb Cell Fact 2005, 4:26.

56. Monath TP, Heinz FX: Flaviviruses. In Fields Virology. Edited by: BN, Knipe DM, Howley PM. Philadelphia: Lippincott-Raven; 1996:961-1034.

57. Estcourt MJ, Ramshaw A, Ramsay AJ: Cytokine responses in virus infections: effects on pathogenesis, recovery and persistence. Curr Opin Microbiol 1998, 1(4):411-418.

58. Li P, Cao RB, Zheng QS, Liu JJ, Li Y, Wang EX, Li F, Chen PY: Enhancement of humoral and cellular immunity in mice against Japanese encephalitis virus using a DNA prime-protein boost vaccine strategy. Vet J 2010, 183(2):210-216.

59. Richmond JF, Lu S, Santoro JC, Weng J, Hu SL, Montefiori DC, Robinson HL: Studies of the neutralizing activity and avidity of anti-human immunodeficiency virus type 1 Env antibody elicited by DNA priming and protein boosting. J Virol 1998, 72(11):9092-9100.

60. Steitz J, Brück J, Knop J, Tüting T: Adenovirus-transduced dendritic cells stimulate cellular immunity to melanoma via a CD4(+) T cell-dependent mechanism. Gene Ther 2001, 8(16):1255-1263.

61. Morita A, Ariizumi K, Ritter R, Jester JV, Kumamoto T, Johnston SA, Takashima A: Development of a Langerhans cell-targeted gene therapy format using a dendritic cell-specific promoter. Gene Ther 2001, 8(22):1729-1737

62. Moutaftsi M, Mehl AM, Borysiewicz LK, Tabi Z: Human cytomegalovirus inhibits maturation and impairs function of monocyte-derived dendritic cells. Blood 2002, 99(8):2913-2921.

63. World Health Organization: Japanese encephalitis vaccines. Wkly Epidemiol Rec 1998, 73(44):337-344.

doi:10.1186/1743-422X-8-382

Cite this article as: Ahsan and Gore: Comparison of immune response generated against Japanese encephalitis virus envelope protein expressed by DNA vaccines under macrophage associated versus ubiquitous expression promoters. Virology Journal 2011 8:382.

\section{Submit your next manuscript to BioMed Central and take full advantage of:}

- Convenient online submission

- Thorough peer review

- No space constraints or color figure charges

- Immediate publication on acceptance

- Inclusion in PubMed, CAS, Scopus and Google Scholar

- Research which is freely available for redistribution

Submit your manuscript at www.biomedcentral.com/submit
C) Biomed Central 